\title{
EFEITO DE TEMPERATURAS E SUBSTRATOS NA GERMINAÇÃO DE SEMENTES DE Myracrodruon urundeuva Fr. All. (ANACARDIACEAE) ${ }^{1}$
}

\author{
Mauro Vasconcelos Pacheco², Valderez Pontes Matos ${ }^{3}$, Rinaldo Luiz Caraciolo Ferreira ${ }^{4}$, Ana Lícia \\ Patriota Feliciano $^{4}$ e Kedma Maria Silva Pinto 5
}

\begin{abstract}
RESUMO - Myracrodruon urundeuva Fr. All. (Anacardiaceae) é uma espécie arbórea nativa que apresenta excelentes propriedades físicas, químicas e biológicas. Entretanto, devido à exploração predatória, está na lista oficial das espécies brasileiras ameaçadas de extinção. Este trabalho teve como objetivo estudar a germinação das sementes de $M$. urundeuva sob diferentes substratos e regimes de temperatura. O delineamento experimental adotado foi o inteiramente casualizado, em arranjo fatorial $8 \times 7$ (oito substratos - entre e sobre: papel mataborrão, areia, vermiculita e pó de coco; sete temperaturas: 25, 27, 30, 35, 20-27, 20-30 e 20-35 ${ }^{\circ} \mathrm{C}$ ), com quatro repetições de 25 sementes cada. Avaliaram-se as seguintes características: germinação (\%), primeira contagem (\%), índice de velocidade de germinação, tempo médio de germinação (dias) e comprimento (cm) do hipocótilo e da raiz primária. Nas temperaturas constantes ocorreram os tempos médios menores de germinação de sementes e desenvolvimento maior do hipocótilo. As temperaturas de 25 e $27^{\circ} \mathrm{C}$ proporcionaram às sementes resultados satisfatórios de germinação em todos os substratos testados, com exceção do substrato entre papel a $27^{\circ} \mathrm{C}$. Os substratos vermiculita e pó de coco permitiram bom desempenho germinativo e não exigiram reumedecimento diário, mostrando-se adequados para a avaliação da qualidade fisiológica de sementes de $M$. urundeuva.
\end{abstract}

Palavras-chave: Sementes florestais, aroeira do sertão e vigor.

\section{EFFECTS OF TEMPERATURE AND SUBSTRATE ON Myracrodruon urundeuva Fr. All. (ANACARDIACEA) SEED GERMINATION}

\begin{abstract}
Myracrodruon urundeuva Fr. All. (Anacardiaceae) is a native tree specie with excellent physical, chemical and biological properties. However, due to predatory exploration, it is in the official list of Brazilian species threatened with extinction. This work aimed at studying the germination of M. urundeuva seeds in different conditions of substrate and temperature regime. The experiment was a completely randomized design in a $8 \times 7$ factorial arrangement ( 7 temperatures 25, 27, 30, 35, 20-27, 20-30 and 20-35 ${ }^{\circ}$; and 8 substrates - sowing in and on: blotting paper, sand, vermiculite and coconut fiber) with four replications with 25 seeds. The following parameters were analyzed: germination (\%), first germination count (\%), germination speed index, average time of germination (days), and length ( $\mathrm{cm}$ ) of hipocotyl and primary root. Constant temperatures gave the shortest average time of seed germination and favored hipocotyl development. The best results for germination were obtained at 25 and $27^{\circ} \mathrm{C}$ in all substrates, except for sowing in between blotting paper at $27^{\circ} \mathrm{C}$. The vermiculite and coconut fiber substrates allowed satisfactory germinative performance and did not require daily remoisten, proving to be suitable for the evaluation of the physiological quality of M. urundeuva seeds.
\end{abstract}

Keywords: Forest seeds, aroeira-do-sertão and vigor.

\footnotetext{
${ }^{1}$ Recebido em 21.10.2004 e aceito para publicação em 05.04.2006.

${ }^{2}$ Programa de Pós-Graduação em Ciências Florestais da UFRPE. E-mail: <pachecomv@ig.com.br>.

${ }^{3}$ Departamento de Agronomia da UFRPE. E-mail: <vpmatos@ig.com.br>.

${ }^{4}$ Departamento de Ciência Florestal da UFRPE. E-mail: <rinaldof@ufrpe.br>.

${ }^{5}$ Programa de Graduação em Agronomia da UFRPE.
} 


\section{INTRODUÇÃO}

Myracrodruon urundeuva Fr. All (aroeira-do-sertão) é uma espécie pertencente à família Anacardiaceae, que apresenta larga distribuição geográfica, podendo ser encontrada no México, Argentina, Bolívia e Paraguai. No Brasil, essa espécie ocorre principalmente na Região Nordeste, podendo atingir entre 5 e $20 \mathrm{~m}$ de altura na Caatinga, Cerrado e em zonas de transição CerradoFloresta Estacional e até $35 \mathrm{~m}$ nas Florestas Pluviais (AWEB, 2004). A madeira apresenta grande resistência mecânica e é praticamente imputrescível, sendo largamente utilizada na construção civil como vigas, ripas, caibros e tacos para assoalho (LORENZI, 1998). Além disso, também são atribuídas atividades medicinais a essa espécie, no tratamento de hemorragias, infecções respiratórias, urinárias e distúrbios no sistema digestório (MATOS, 1999). Alguns estudos (RODRIGUES, 1999; ALBUQUERQUE et al., 2004) também têm comprovado efeitos antiinflamatórios e cicatrizantes.

Devido às excelentes propriedades físicas, químicas e biológicas, $M$. urundeuva é muito explorada, tornandose escassa, e está na lista oficial das espécies brasileiras ameaçadas de extinção, na categoria vulnerável (IBAMA, 1992). Esse tipo de exploração extrativista pode gerar perdas de material genético e comprometer a preservação e a conservação das populações de $M$. urundeuva dentro de seus "habitats".

Dentre os principais aspectos que servem de base para o manejo de florestas nativas, está a germinação de sementes como subsídio tanto para a compreensão da regeneração natural (LANDGRAF, 1994) quanto para a tecnologia de sementes florestais.

A germinação das sementes é influenciada por fatores ambientais, como temperatura e substrato, os quais podem ser manipulados, a fim de otimizar a porcentagem, velocidade e uniformidade de germinação, resultando na obtenção de plântulas mais vigorosas e na redução de gastos de produção (NASSIF et al., 2004).

A temperatura é um dos fatores que apresentam grande influência tanto na porcentagem de germinação quanto na determinação do vigor das plântulas, influenciando a absorção de água pela semente e as reações bioquímicas que regulam todo o processo metabólico (BEWLEY e BLACK, 1994).

O comportamento das sementes em relação à temperatura ótima é bastante variável entre as espécies florestais. A maioria das espécies tropicais apresenta bom desempenho germinativo na faixa de 20 a $30^{\circ} \mathrm{C}$ (BORGES e RENA, 1993), podendo variar de acordo com as temperaturas encontradas em sua região de origem. Para determinadas espécies, o desempenho germinativo das sementes é favorecido por temperaturas constantes, como em Genipa americana L. (ANDRADE et al., 2000), por alternância de temperatura, a exemplo de Sebastiania commersoniana (Baill.) Smith \& Downs (SANTOS e AGUIAR, 2000) e por insensibilidade ao regime de temperatura utilizado, como foi observado nas sementes de Vochysia haenkiana Mart. (SILVA et al., 2000). Essas características estão diretamente associadas ao comportamento ecológico das espécies nos seus "habitats" (ALBUQUERQUE et al., 2003).

O substrato tem a função de suprir as sementes de umidade e proporcionar condições adequadas à germinação delas e ao posterior desenvolvimento das plântulas (FIGLIOLIA et al., 1993), devendo manter uma proporção adequada entre a disponibilidade de água e a aeração e, assim, evitar a formação de uma película aquosa sobre a semente, que impede a penetração de oxigênio(POPINIGIS, 1985) e contribui para a proliferação de patógenos.

Ao escolher um substrato, alguns aspectos devem ser considerados, como o tamanho da semente, a exigência com relação à umidade e à luz, a facilidade que ele oferece durante a instalação, a realização das contagens e a avaliação das plântulas (BRASIL, 1992). Alguns dos substratos prescritos e recomendados nas Regras para Análise de Sementes (BRASIL, 1992) são: papel (toalha, filtro, mata-borrão), solo e areia. Entretanto, existem poucas recomendações para as espécies florestais, e outros tipos de substratos são testados, como o Plantmax® (OLIVEIRAet al., 2003), a vermiculita (ALVES et al., 2002) e o pó de coco (LACERDA et al., 2003).

Conhecer as condições que proporcionem germinação rápida e uniforme das sementes é extremamente útil para fins de semeadura. A germinação rápida e o desenvolvimento homogêneo de plântulas reduzem os cuidados por parte dos viveiristas, uma vez que as mudas se desenvolverão mais rapidamente, promovendo um povoamento mais uniforme no campo, onde estarão expostas às condições adversas do ambiente.

Este trabalho teve como objetivo estudar os efeitos de diferentes temperaturas e substratos sobre o comportamento germinativo de sementes de $M$. urundeuva. 


\section{MATERIAL E MÉTODOS}

Os frutos de Myracrodruon urundeuva Fr. All. (Foto 1) foram coletados diretamente de 10 árvoresmatriz localizadas na Estação Experimental da Empresa Pernambucana de Pesquisa Agropecuária (IPA), em Serra Talhada, PE, em outubro de 2003. Foram encaminhados ao Laboratório de Sementes do Departamento de Agronomia da Universidade Federal Rural de Pernambuco, para beneficiamento manual, que consistiu na remoção dos cálices, e, em seguida, os frutos foram homogeneizados. As drupas apresentaram teor de água de $8 \%$, as quais foram acondicionadas em recipientes de vidro e armazenadas durante dois meses em ambiente de laboratório, quando teve início a instalação do experimento.

Os testes de germinação foram conduzidos em germinadores tipo BOD regulados para os regimes de temperaturas constantes de $25,27,30$ e $35^{\circ} \mathrm{C}$ e alternadas de 20-27, 20-30 e 20-35 ${ }^{\circ} \mathrm{C}$ com fotoperíodo de 8 horas, utilizando-se lâmpadas fluorescentes tipo luz do dia $(4 \times 20 \mathrm{~W})$. Para as temperaturas alternadas, o período luminoso ocorreu à temperatura mais alta.

As sementes foram escarificadas mecanicamente com lixa $\mathrm{n}^{\circ} 60$, segundo recomendações de Nunes et al. (2002), e desinfestadas com hipoclorito de sódio $5 \%$ durante 5 minutos e, em seguida, lavadas com água destilada. A semeadura foi feita entre e sobre os substratos papel mata-borrão, areia, vermiculita e pó de coco, previamente autoclavados, umedecidos com solução de Nistatina $0,2 \%$ e distribuídos em caixas plásticas transparentes de 11 x 11 x $3 \mathrm{~cm}$, com tampa.

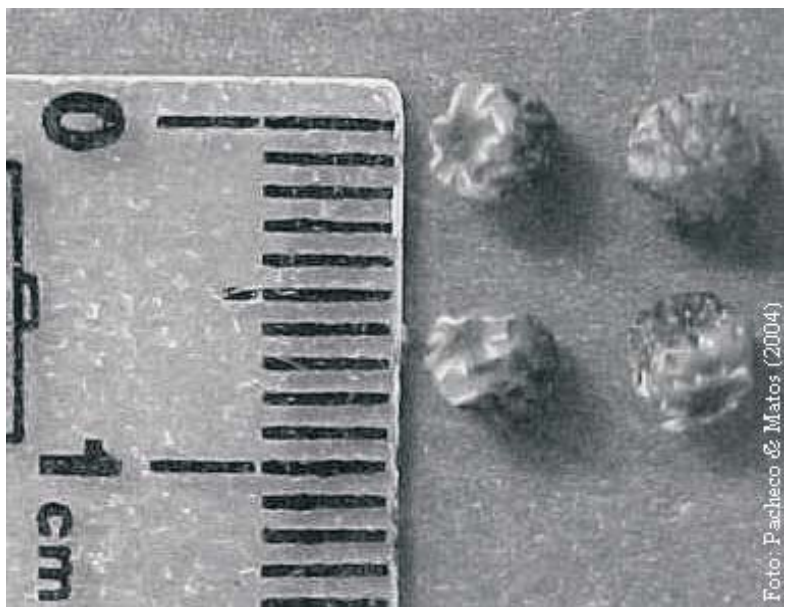

Foto 1 - Frutos de Myracrodruon urundeuva Fr. All. Photo 1 - Myracrodruon urundeuva Fr. All. fruits.
Em relação ao substrato entre papel mata-borrão, foi posta uma folha de papel-toalha sobre as sementes.

O número de sementes germinadas foi avaliado diariamente, adotando-se como critério de germinação a emergência dos cotilédones, com o conseqüente surgimento do hipocótilo. Avaliaram-se as seguintes características: germinação - correspondente à porcentagem total de sementes germinadas até o $10^{\circ}$ dia após a semeadura (Foto 2 ); primeira contagem - correspondente à porcentagem de sementes germinadas até o $2^{\circ}$ dia após o início do teste; índice de velocidade de germinação (IVG) - determinado de acordo com a fórmula apresentada por Maguire (1962); tempo médio de germinação (TMG) - de acordo com a fórmula citada por Silva e Nakagawa (1995), com o resultado expresso em dias após a semeadura; comprimento do hipocótilo e da raiz primária - o hipocótilo e a raiz primária das plântulas normais de cada repetição foram medidos com o auxílio de uma régua graduada em centímetros.

A análise de variância do experimento foi realizada segundo o delineamento experimental inteiramente casualizado, com os tratamentos distribuídos em arranjo fatorial $7 \times 8$ (sete temperaturas e oito substratos), com quatro repetições de 25 sementes cada.
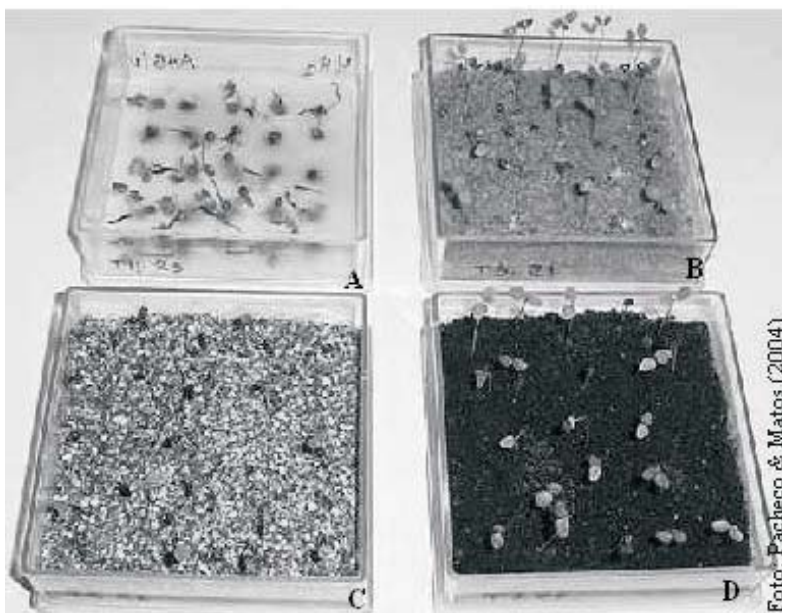

Foto 2 - Plântulas de Myracrodruon urundeuva Fr. All. oriundas de sementes submetidas a $25^{\circ} \mathrm{C}$, entre os substratos papel (A), areia (B), vermiculita (C) e pó de coco (D), aos 10 dias após a semeadura.

Photo 2 - Myracrodruon urundeuva Fr. All. seedlings derived from seeds subjected at $25^{\circ} C$, in substrates: blotting paper $(A)$, sand $(B)$, vermiculite $(C)$ and coconut fiber $(D), 10$ days after sowing.

R. Árvore, Viçosa-MG, v.30, n.3, p.359-367, 2006 
Para a análise dos dados, foi utilizado o software estatístico The SAS System for Windows (Statistical Analysis System), versão 8.02. SAS Institute Inc, 19992001, Cary, NC, USA. As médias foram comparadas pelo teste de Scott-Knott a 5\% de probabilidade. Não houve necessidade de transformações dos dados, de acordo com os testes de normalidade e homogeneidade de variâncias.

\section{RESULTADOS E DISCUSSÃO}

Neste estudo, as drupas de $M$. urundeuva, caracterizadas por Barroso et al. (1999) como frutos globosos, resinosos, contendo apenas um putâmen, foram referidas como sementes para facilitar a compreensão do texto.

Verificou-se interação significativa $(\mathrm{P}<0,05)$ entre substrato e temperatura para todas as características avaliadas, exceto para o tempo médio de germinação ( $\mathrm{P}>0,05)$, no qual os efeitos dos fatores estudados se revelaram independentes.

Em relação à porcentagem de germinação (Quadro 1 ), realizada no $10^{\circ}$ dia após a semeadura, constatouse que as temperaturas constantes de 25 e $27^{\circ} \mathrm{C}$ proporcionaram às sementes taxa elevada de germinação (variando entre 79 e $93 \%$ ) em todos os substratos testados. Também foi constatado que a $35^{\circ} \mathrm{C}$, independentemente do tipo de substrato, não houve resultados satisfatórios de germinação. Dentre as temperaturas alternadas, apenas $20-27^{\circ} \mathrm{C}$, quando combinadas com os substratos entre e sobre papel, entre e sobre vermiculita e sobre pó de coco, proporcionou bons resultados sobre a germinação. Avaliando os substratos utilizados, apenas sobre vermiculita em todas as temperaturas, exceto a $35^{\circ} \mathrm{C}$, constatou-se que eles proporcionaram porcentagem média de $80 \%$ de germinação de sementes de M. urundeuva.

Com relação aos dados da primeira contagem da germinação (Quadro 2), realizada no $2^{\circ}$ dia após a semeadura, os valores maiores ocorreram a $27^{\circ} \mathrm{C}$, com o uso dos substratos entre vermiculita (48\%) e entre e sobre pó de coco (49 e 56\%, respectivamente) e a $25^{\circ} \mathrm{C}$ nos substratos entre e sobre pó de coco (44 e $42 \%$, respectivamente). Ao contrário do que foi observado em relação às temperaturas alternadas, nas constantes foram alcançados resultados melhores de germinação de sementes.

Em relação ao índice de velocidade de germinação (IVG) (Quadro 3), as combinações ideais entre temperatura e substrato foram: entre e sobre papel a 35 e 20-27 ${ }^{\circ} \mathrm{C}$; entre vermiculita a 27,30 e $20-27^{\circ} \mathrm{C}$; sobre vermiculita a $27^{\circ} \mathrm{C}$; e entre e sobre pó de coco a 25 e $27^{\circ} \mathrm{C}$. Dentre as temperaturas testadas, os substratos entre e sobre areia proporcionaram às sementes índices maiores de velocidade de germinação apenas quando submetidas a 25 e $27^{\circ} \mathrm{C}$.

Quadro 1 - Germinação (\%) de sementes de Myracrodruon urundeuva Fr. All. submetidas a diferentes temperaturas e substratos Table 1 - Germination (\%) of Myracrodruon urundeuva Fr. All. seeds subjected at different temperatures and in different substrates

\begin{tabular}{lccccccc}
\hline Substratos & \multicolumn{7}{c}{ Temperatura ('C) } \\
\hline E-P & $\mathbf{2 5}$ & $\mathbf{2 7}$ & $\mathbf{3 0}$ & $\mathbf{3 5}$ & $\mathbf{2 0 - 2 7}$ & $\mathbf{2 0 - 3 0}$ & $\mathbf{2 0 - 3 5}$ \\
$\mathbf{S - P}$ & $89 \mathrm{Aa}$ & $73 \mathrm{Ab}$ & $54 \mathrm{Bc}$ & $58 \mathrm{Ac}$ & $90 \mathrm{Aa}$ & $60 \mathrm{Bc}$ & $22 \mathrm{Cd}$ \\
E-A & $91 \mathrm{Aa}$ & $80 \mathrm{Aa}$ & $71 \mathrm{Ab}$ & $58 \mathrm{Ac}$ & $87 \mathrm{Aa}$ & $73 \mathrm{Ab}$ & $56 \mathrm{Bc}$ \\
S-A & $84 \mathrm{Aa}$ & $86 \mathrm{Aa}$ & $28 \mathrm{Cc}$ & $19 \mathrm{Bc}$ & $61 \mathrm{Bb}$ & $21 \mathrm{Dc}$ & $2 \mathrm{Dd}$ \\
E-V & $93 \mathrm{Aa}$ & $81 \mathrm{Aa}$ & $53 \mathrm{Bb}$ & $32 \mathrm{Bc}$ & $58 \mathrm{Bb}$ & $30 \mathrm{Dc}$ & $20 \mathrm{Cc}$ \\
S-V & $85 \mathrm{Aa}$ & $90 \mathrm{Aa}$ & $82 \mathrm{Aa}$ & $39 \mathrm{Bc}$ & $91 \mathrm{Aa}$ & $62 \mathrm{Bb}$ & $61 \mathrm{Bb}$ \\
E-C & $82 \mathrm{Aa}$ & $79 \mathrm{Aa}$ & $74 \mathrm{Aa}$ & $42 \mathrm{Bb}$ & $89 \mathrm{Aa}$ & $79 \mathrm{Aa}$ & $79 \mathrm{Aa}$ \\
S-C & $89 \mathrm{Aa}$ & $82 \mathrm{Aa}$ & $35 \mathrm{Cb}$ & $26 \mathrm{Bb}$ & $74 \mathrm{Ba}$ & $45 \mathrm{Cb}$ & $36 \mathrm{Cb}$ \\
\hline
\end{tabular}

Médias seguidas pela mesma letra maiúscula na coluna e minúscula na linha não diferem entre si, pelo teste de Scott-Knott a 5\% $(\mathrm{CV}=17,2 \%)$. Entre papel (E-P), Sobre papel (S-P), Entre areia (E-A), Sobre areia (S-A), Entre vermiculita (E-V), Sobre vermiculita (S-V), Entre pó de coco (E-C) e Sobre pó de coco (S-C).

R. Árvore, Viçosa-MG, v.30, n.3, p.359-367, 2006 
Quadro 2 - Primeira contagem (\%) da germinação de sementes de Myracrodruon urundeuva Fr. All. submetidas a diferentes temperaturas e substratos

Table 2 - First germination count (\%) of Myracrodruon urundeuva Fr. All. subjected at different temperatures and in different substrates

\begin{tabular}{lccccccc}
\hline Substratos & \multicolumn{7}{c}{ Temperatura $\left.\mathbf{(}^{\mathbf{C}} \mathbf{C}\right)$} \\
\hline $\mathbf{E - P}$ & $\mathbf{2 5}$ & $\mathbf{2 7}$ & $\mathbf{3 0}$ & $\mathbf{3 5}$ & $\mathbf{2 0 - 2 7}$ & $\mathbf{2 0 - 3 0}$ & $\mathbf{2 0 - 3 5}$ \\
$\mathbf{S - P}$ & $7 \mathrm{Bb}$ & $30 \mathrm{Ba}$ & $23 \mathrm{Ca}$ & $36 \mathrm{Aa}$ & $0 \mathrm{Ab}$ & $1 \mathrm{Ab}$ & $0 \mathrm{Ab}$ \\
$\mathbf{E}-\mathbf{A}$ & $7 \mathrm{Bb}$ & $15 \mathrm{Cb}$ & $31 \mathrm{Ba}$ & $35 \mathrm{Aa}$ & $1 \mathrm{Ac}$ & $0 \mathrm{Ac}$ & $0 \mathrm{Ac}$ \\
$\mathbf{S}-\mathbf{A}$ & $20 \mathrm{Bb}$ & $32 \mathrm{Ba}$ & $4 \mathrm{Dc}$ & $5 \mathrm{Cc}$ & $2 \mathrm{Ac}$ & $0 \mathrm{Ac}$ & $0 \mathrm{Ac}$ \\
$\mathbf{E}-\mathbf{V}$ & $10 \mathrm{Bc}$ & $33 \mathrm{Ba}$ & $22 \mathrm{Cb}$ & $17 \mathrm{Cb}$ & $3 \mathrm{Ac}$ & $3 \mathrm{Ac}$ & $0 \mathrm{Ac}$ \\
S-V & $15 \mathrm{Bb}$ & $48 \mathrm{Aa}$ & $48 \mathrm{Aa}$ & $25 \mathrm{Bb}$ & $1 \mathrm{Ac}$ & $1 \mathrm{Ac}$ & $4 \mathrm{Ac}$ \\
$\mathbf{E}-\mathbf{C}$ & $14 \mathrm{Bb}$ & $37 \mathrm{Ba}$ & $42 \mathrm{Aa}$ & $20 \mathrm{Cb}$ & $0 \mathrm{Ac}$ & $3 \mathrm{Ac}$ & $10 \mathrm{Ab}$ \\
S-C & $44 \mathrm{Aa}$ & $49 \mathrm{Aa}$ & $9 \mathrm{Db}$ & $12 \mathrm{Cb}$ & $3 \mathrm{Ab}$ & $0 \mathrm{Ab}$ & $3 \mathrm{Ab}$ \\
\hline
\end{tabular}

Médias seguidas pela mesma letra maiúscula na coluna e minúscula na linha não diferem entre si, pelo teste de Scott-Knott a 5\% $(\mathrm{CV}=47,4 \%)$. Entre papel $(\mathrm{E}-\mathrm{P})$, Sobre papel $(\mathrm{S}-\mathrm{P})$, Entre areia (E-A), Sobre areia (S-A), Entre vermiculita (E-V), Sobre vermiculita $(\mathrm{S}-\mathrm{V})$, Entre pó de coco (E-C) e Sobre pó de coco $(\mathrm{S}-\mathrm{C})$.

Quadro 3 - Índice de velocidade de germinação de sementes de Myracrodruon urundeuva Fr. All., submetidas a diferentes temperaturas e substratos

Table 3 - Germination speed index of Myracrodruon urundeuva Fr. All. seeds subjected at different temperatures and in different substrates

\begin{tabular}{lccccccc}
\hline Substratos & \multicolumn{7}{c}{ Temperatura $\left({ }^{\circ} \mathbf{C}\right)$} \\
\hline E-P & $\mathbf{2 5}$ & $\mathbf{2 7}$ & $\mathbf{3 0}$ & $\mathbf{3 5}$ & $\mathbf{2 0 - 2 7}$ & $\mathbf{2 0 - 3 0}$ & $\mathbf{2 0 - 3 5}$ \\
$\mathbf{S - P}$ & $5,22 \mathrm{Ba}$ & $4,80 \mathrm{Ba}$ & $3,84 \mathrm{Da}$ & $4,88 \mathrm{Aa}$ & $4,80 \mathrm{Aa}$ & $3,05 \mathrm{Bb}$ & $1,02 \mathrm{Dc}$ \\
$\mathbf{E - A}$ & $5,17 \mathrm{Ba}$ & $4,46 \mathrm{Ba}$ & $4,86 \mathrm{Ca}$ & $4,27 \mathrm{Aa}$ & $4,63 \mathrm{Aa}$ & $3,79 \mathrm{Ab}$ & $2,77 \mathrm{Bb}$ \\
S-A & $4,71 \mathrm{Ba}$ & $5,59 \mathrm{Ba}$ & $1,40 \mathrm{Fb}$ & $1,96 \mathrm{Cb}$ & $2,49 \mathrm{Bb}$ & $0,89 \mathrm{Cc}$ & $0,56 \mathrm{Dc}$ \\
E-V & $4,95 \mathrm{Ba}$ & $5,49 \mathrm{Ba}$ & $3,50 \mathrm{Db}$ & $2,49 \mathrm{Cc}$ & $2,70 \mathrm{Bc}$ & $1,74 \mathrm{Cd}$ & $0,08 \mathrm{Dd}$ \\
S-V & $4,89 \mathrm{Ba}$ & $6,48 \mathrm{Aa}$ & $6,92 \mathrm{Aa}$ & $3,34 \mathrm{Bc}$ & $5,09 \mathrm{Aa}$ & $3,19 \mathrm{Bb}$ & $3,40 \mathrm{Bb}$ \\
E-C & $4,83 \mathrm{Bb}$ & $5,39 \mathrm{Aa}$ & $5,79 \mathrm{Ba}$ & $3,49 \mathrm{Bc}$ & $4,72 \mathrm{Ab}$ & $4,43 \mathrm{Ab}$ & $4,53 \mathrm{Ab}$ \\
S-C & $6,32 \mathrm{Aa}$ & $6,38 \mathrm{Aa}$ & $2,60 \mathrm{Ec}$ & $2,61 \mathrm{Cc}$ & $3,45 \mathrm{Bb}$ & $1,89 \mathrm{Cc}$ & $1,94 \mathrm{Cc}$ \\
\hline
\end{tabular}

Médias seguidas pela mesma letra maiúscula na coluna e minúscula na linha não diferem entre si, pelo teste de Scott-Knott a 5\% (CV $=18,5 \%)$. Entre papel (E-P), Sobre papel (S-P), Entre areia (E-A), Sobre areia (S-A), Entre vermiculita (E-V), Sobre vermiculita (S-V), Entre pó de coco (E-C) e Sobre pó de coco (S-C).

A temperatura ótima para a germinação de sementes está diretamente associada às características ecológicas da espécie (PROBERT, 1992). Nas temperaturas constantes, obtiveram-se porcentagem e velocidade maiores de germinação das sementes, em comparação com as temperaturas alternadas. $\mathrm{O}$ fato de ocorrer germinação em ambos os regimes de temperatura indica que as sementes dessa espécie são capazes de germinar em pequenas clareiras, evidenciando uma adaptação às flutuações térmicas naturais do ambiente. No entanto, preferem condições de sub-bosque, nas quais predominam amplitudes térmicas menores. Essas características conferem à $M$. urundeuva capacidade maior de estabelecimento das plântulas em campo, tornandoas capazes de suportar as condições adversas do ambiente.

Os tempos menores médios de germinação (TMG) (Quadro 4) foram alcançados quando as sementes foram

R. Árvore, Viçosa-MG, v.30, n.3, p.359-367, 2006 
submetidas às temperaturas constantes, bem como nos substratos entre papel e pó de coco ( 4,4 dias), entre e sobre vermiculita (4,2 dias) e sobre pó de coco ( 4,1 dias). Diante desses resultados, recomenda-se que o teste de germinação seja encerrado no $5^{\circ}$ dia após a semeadura.

O vigor, avaliado pelo comprimento do hipocótilo (Quadro 5), demonstrou que apenas nas temperaturas constantes foram observadas combinações satisfatórias com os substratos. Os substratos entre pó de coco nas temperaturas de $25(3,4 \mathrm{~cm}), 27(3,2 \mathrm{~cm})$ e $35^{\circ} \mathrm{C}$ $(3,5 \mathrm{~cm})$ e sobre pó de coco a $25^{\circ} \mathrm{C}(3,1 \mathrm{~cm})$ proporcionaram às plântulas maior desenvolvimento da parte aérea. Silveira et al. (2002), ao utilizarem o pó de coco para produção de mudas de tomateiro, também detectaram, além de taxa elevada na germinação das sementes, incrementos no comprimento da parte aérea das plântulas.

Para o comprimento da raiz primária (Quadro 6), foi observado que a utilização dos substratos entre e sobre areia a $27^{\circ} \mathrm{C}$, entre vermiculita a $20-35^{\circ} \mathrm{C}$, bem como o pó de coco em todas as temperaturas, exceto sobre pó de coco a $20-35{ }^{\circ} \mathrm{C}$, proporcionou o desenvolvimento melhor do sistema radicular das plântulas de aroeira-do-sertão.

Quadro 4 - Tempo médio de germinação (dias) de sementes de Myracrodruon urundeuva Fr. All. submetidas a diferentes temperaturas e substratos

Table 4-Average time of germination (days) of Myracrodruon urundeuva Fr. All. seeds subjected at different temperatures and in different substrates

\begin{tabular}{ccccccccc}
\hline & & \multicolumn{7}{c}{ Temperatura $\left({ }^{\mathbf{C}} \mathbf{C}\right)$} \\
\hline & $\mathbf{2 5}$ & $\mathbf{2 7}$ & $\mathbf{3 0}$ & $\mathbf{3 5}$ & $\mathbf{2 0 - 2 7}$ & $\mathbf{2 0 - 3 0}$ & $\mathbf{2 0 - 3 5}$ & \\
TMG (dias) & $4,4 \mathrm{~b}$ & $4,0 \mathrm{~b}$ & $4,0 \mathrm{~b}$ & $3,1 \mathrm{c}$ & $5,3 \mathrm{a}$ & $5,3 \mathrm{a}$ & $4,9 \mathrm{a}$ & \\
\hline & & \multicolumn{7}{c}{ Substratos } \\
\hline & E-P & S-P & E-A & S-A & E-V & S-V & E-C & S-C \\
TMG (dias) & $4,4 \mathrm{~b}$ & $4,6 \mathrm{a}$ & $4,9 \mathrm{a}$ & $4,6 \mathrm{a}$ & $4,2 \mathrm{~b}$ & $4,2 \mathrm{~b}$ & $4,4 \mathrm{~b}$ & $4,1 \mathrm{~b}$ \\
\hline
\end{tabular}

Médias seguidas pela mesma letra não diferem entre si, pelo teste de Scott-Knott a 5\% (CV = 21,7\%). Entre papel (E-P), Sobre papel (S-P), Entre areia (E-A), Sobre areia (S-A), Entre vermiculita (E-V), Sobre vermiculita (S-V), Entre pó de coco (E-C), e Sobre pó de coco (S-C).

Quadro 5-Comprimento (cm) do hipocótilo de plântulas de Myracrodruon urundeuva Fr. All. oriundas de sementes submetidas a diferentes temperaturas e substratos

Table 5 - Hipocotyl lenght (cm) of Myracrodruon urundeuva Fr. All. seedlings derived from seeds subjected at different temperatures and in different substrates

\begin{tabular}{lccccccc}
\hline Substratos & \multicolumn{7}{c}{ Temperatura ('C) } \\
\hline & $\mathbf{2 5}$ & $\mathbf{2 7}$ & $\mathbf{3 0}$ & $\mathbf{3 5}$ & $\mathbf{2 0 - 2 7}$ & $\mathbf{2 0 - 3 0}$ & $\mathbf{2 0 - 3 5}$ \\
$\mathbf{E - P}$ & $2,4 \mathrm{Ba}$ & $2,3 \mathrm{Ca}$ & $2,2 \mathrm{Ba}$ & $2,6 \mathrm{Ba}$ & $1,9 \mathrm{Ab}$ & $1,9 \mathrm{Bb}$ & $1,9 \mathrm{Bb}$ \\
$\mathbf{S - P}$ & $2,5 \mathrm{Ba}$ & $2,1 \mathrm{Db}$ & $2,0 \mathrm{Bb}$ & $2,4 \mathrm{Ca}$ & $1,8 \mathrm{Ab}$ & $1,8 \mathrm{Bb}$ & $2,1 \mathrm{Bb}$ \\
$\mathbf{E}-\mathbf{A}$ & $2,8 \mathrm{Ba}$ & $2,4 \mathrm{Cb}$ & $2,0 \mathrm{Bc}$ & $2,8 \mathrm{Ba}$ & $1,7 \mathrm{Ac}$ & $1,9 \mathrm{Bc}$ & $0,6 \mathrm{Dd}$ \\
$\mathbf{S}-\mathbf{A}$ & $2,4 \mathrm{Ba}$ & $2,0 \mathrm{Da}$ & $1,5 \mathrm{Cb}$ & $2,3 \mathrm{Ca}$ & $1,3 \mathrm{Bc}$ & $1,7 \mathrm{Bb}$ & $1,1 \mathrm{Cc}$ \\
$\mathbf{E}-\mathbf{V}$ & $2,7 \mathrm{Ba}$ & $2,6 \mathrm{Ba}$ & $2,5 \mathrm{Aa}$ & $2,8 \mathrm{Ba}$ & $2,0 \mathrm{Ab}$ & $2,1 \mathrm{Ab}$ & $2,4 \mathrm{Ab}$ \\
$\mathbf{S - V}$ & $2,4 \mathrm{Ba}$ & $1,9 \mathrm{Db}$ & $1,9 \mathrm{Bb}$ & $2,7 \mathrm{Ba}$ & $1,6 \mathrm{Bb}$ & $1,9 \mathrm{Bb}$ & $1,9 \mathrm{Bb}$ \\
$\mathbf{E}-\mathbf{C}$ & $3,4 \mathrm{Aa}$ & $3,2 \mathrm{Aa}$ & $2,7 \mathrm{Ab}$ & $3,5 \mathrm{Aa}$ & $2,1 \mathrm{Ac}$ & $2,4 \mathrm{Ab}$ & $2,4 \mathrm{Ab}$ \\
S-C & $3,1 \mathrm{Aa}$ & $2,6 \mathrm{Bb}$ & $2,2 \mathrm{Bc}$ & $2,8 \mathrm{Bb}$ & $1,8 \mathrm{Ad}$ & $2,1 \mathrm{Ac}$ & $2,3 \mathrm{Ac}$ \\
\hline
\end{tabular}

Médias seguidas pela mesma letra maiúscula na coluna e minúscula na linha não diferem entre si pelo teste de Scott-Knott a $5 \%$ (CV $=11,4 \%)$. Entre papel (E-P), Sobre papel (S-P), Entre areia (E-A), Sobre areia (S-A), Entre vermiculita (E-V), Sobre vermiculita (S-V), Entre pó de coco (E-C), e Sobre pó de coco (S-C).

R. Árvore, Viçosa-MG, v.30, n.3, p.359-367, 2006 
Quadro 6 - Comprimento (cm/plântula) da raiz primária de plântulas de Myracrodruon urundeuva Fr. All. oriundas de sementes submetidas a diferentes temperaturas e substratos

Table 6 - Primary root lenght (cm/seedling) of Myracrodruon urundeuva Fr. All. seedlings derived from seeds subjected at different temperatures and in different substrates

\begin{tabular}{lccccccc}
\hline Substratos & \multicolumn{7}{c}{ Temperatura ('C) } \\
\hline E-P & $\mathbf{2 5}$ & $\mathbf{2 7}$ & $\mathbf{3 0}$ & $\mathbf{3 5}$ & $\mathbf{2 0}-\mathbf{2 7}$ & $\mathbf{2 0}-\mathbf{3 0}$ & $\mathbf{2 0}-\mathbf{3 5}$ \\
$\mathbf{S - P}$ & $1,5 \mathrm{Ca}$ & $2,6 \mathrm{Ba}$ & $1,9 \mathrm{Ba}$ & $2,1 \mathrm{Ba}$ & $1,9 \mathrm{Ba}$ & $1,5 \mathrm{Ba}$ & $0,7 \mathrm{Ba}$ \\
$\mathbf{E}-\mathbf{A}$ & $1,6 \mathrm{Ca}$ & $2,2 \mathrm{Ba}$ & $2,2 \mathrm{Ba}$ & $1,7 \mathrm{Ba}$ & $1,9 \mathrm{Ba}$ & $1,1 \mathrm{Ba}$ & $0,9 \mathrm{Ba}$ \\
$\mathbf{S}-\mathbf{A}$ & $3,2 \mathrm{Ba}$ & $4,2 \mathrm{Aa}$ & $2,1 \mathrm{Bb}$ & $2,3 \mathrm{Bb}$ & $1,5 \mathrm{Bb}$ & $1,7 \mathrm{Bb}$ & $0,3 \mathrm{Bc}$ \\
$\mathbf{E}-\mathbf{V}$ & $2,9 \mathrm{Bb}$ & $4,0 \mathrm{Aa}$ & $2,4 \mathrm{Bb}$ & $2,4 \mathrm{Bb}$ & $1,0 \mathrm{Bc}$ & $1,5 \mathrm{Bc}$ & $0,9 \mathrm{Bc}$ \\
$\mathbf{S}-\mathbf{V}$ & $2,9 \mathrm{Ba}$ & $3,2 \mathrm{Ba}$ & $2,3 \mathrm{Ba}$ & $2,1 \mathrm{Ba}$ & $1,7 \mathrm{Ba}$ & $1,8 \mathrm{Ba}$ & $2,0 \mathrm{Aa}$ \\
E-C & $2,5 \mathrm{Ba}$ & $3,0 \mathrm{Ba}$ & $2,3 \mathrm{Ba}$ & $2,6 \mathrm{Ba}$ & $1,4 \mathrm{Ba}$ & $1,8 \mathrm{Ba}$ & $1,8 \mathrm{Aa}$ \\
S-C & $4,1 \mathrm{Aa}$ & $4,4 \mathrm{Aa}$ & $4,9 \mathrm{Aa}$ & $3,8 \mathrm{Aa}$ & $3,8 \mathrm{Aa}$ & $3,4 \mathrm{Aa}$ & $2,9 \mathrm{Aa}$ \\
\hline
\end{tabular}

Médias seguidas pela mesma letra maiúscula na coluna e minúscula na linha não diferem entre si, pelo teste de Scott-Knott a $5 \%$ (CV $=14,0 \%)$. Entre papel (E-P), Sobre papel (S-P), Entre areia (E-A), Sobre areia (S-A), Entre vermiculita (E-V), Sobre vermiculita (S-V), Entre pó de coco (E-C) e Sobre pó de coco (S-C).

Apesar dos resultados de germinação satisfatórios obtidos com as temperaturas de 25 e $27^{\circ} \mathrm{C}$, observouse menor capacidade de retenção de água, tanto nos substratos sobre e entre papel quanto sobre e entre areia, sendo necessária reposição diária de água durante a condução dos testes. Consta nas Regras para Análise de Sementes (BRASIL, 1992) que se deve evitar, sempre que possível, o reumedecimento dos substratos após a semeadura, uma vez que pode causar variações adicionais aos resultados. Segundo Figliolia et al. (1993), a areia também apresenta o inconveniente de drenar a água, acarretando ressecamento na parte superior do substrato, além de ser muito pesada, o que dificulta o manuseio das caixas plásticas no germinador.

A vermiculita é um substrato que vem sendo utilizado com bons resultados para a germinação de sementes de espécies florestais (FIGLIOLIA et al., 1993; SILVA et al., 2002), bem como, mais recentemente, o pó de coco (LACERDA et al., 2003). Ambos os substratos são leves, de fácil manuseio, com boa capacidade de absorção de água, não exigem o reumedecimento diário e proporcionam bom desempenho germinativo das sementes.

Na Europa e nos Estados Unidos, o pó de coco tem sido importado, principalmente do Sri Lanka, em larga escala para substituir a turfa na horticultura intensiva (VAVRINA et al., 1996). O pó de coco destacase por apresentar propriedades físicas que lhe conferem características muito satisfatórias à sua utilização como substrato, como alta porosidade $(95,6 \%)$, ótima capacidade de retenção de água (538 mL/L) e de aeração (45,5\%), sendo que as fibras do pó de coco são, praticamente, inertes e não possuem os nutrientes essenciais para o desenvolvimento das plântulas, apresentando também outras vantagens, como o baixo custo e a ampla disponibilidade no Nordeste do Brasil (CARRIJO et al., 2002).

\section{CONCLUSÕES}

- Nas temperaturas constantes, ocorreram os tempos médios menores de germinação de sementes e desenvolvimento maior do hipocótilo de Myracrodruon urundeuva.

- Considerando os testes de germinação e de vigor, as temperaturas de $25 \mathrm{e} 27^{\circ} \mathrm{C}$ proporcionaram às sementes de $M$. urundeuva resultados satisfatórios de germinação em todos os substratos testados, com exceção do substrato entre papel a $27^{\circ} \mathrm{C}$.

- Os substratos vermiculita e pó de coco permitiram bom desempenho germinativo e não exigiram reumedecimento diário, mostrando-se mais adequados para avaliação da qualidade fisiológica de sementes de M. urundeuva.

\section{AGRADECIMENTOS}

Ao CNPq (Conselho Nacional de Desenvolvimento Científico e Tecnológico), pelas bolsas concedidas para pesquisador e estudante de pós-graduação.

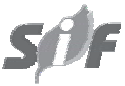

R. Árvore, Viçosa-MG, v.30, n.3, p.359-367, 2006 


\section{REFERÊNCIAS BIBLIOGRÁFICAS}

ALBUQUERQUE, M. C. F.; COELHO, M. F. B.; ALBRECTH, J. M. F. Germinação de sementes de espécies medicinais do Cerrado. In: COELHO, M. F. B. et al. Diversos olhares em etnobiologia, etnoecologia e plantas medicinais. Cuiabá: UNICEN Publicações, 2003. p. 157-181.

ALBUQUERQUE, R. J. M.; RODRIGUES, L. V.; VIANA, G. S. B. Análise clínica e morfológica da conjuntivite alérgica induzida por ovalbumina e tratada com chalcona em cobaias. Acta Cirúrgica Brasileira, v. 19, n. 1, p. 43-68, 2004.

ALVES, E. U. et al. Germinação de sementes de Mimosa caesalpiniaefolia Benth. em diferentes substratos e temperaturas. Revista Brasileira de Sementes, v. 24, n. 1, p. 169-178, 2002.

ANDRADE, A. C. S. et al. Germinação de sementes de jenipapo: temperatura, substrato e morfologia no desenvolvimento pós-seminal. Pesquisa Agropecuária Brasileira, v. 35, n. 3, p. 609-615, 2000.

AWEB. Myracrodruon urundeuva Fr. All. Disponível em: <http://www.alicesoftware.com/ webs/trees/aweb/td001/td_00045.htm>. Acesso em: 26 ago. 2004.

BARROSO, G. M. et al. Frutos e sementes: morfologia aplicada à sistemática de dicotiledôneas. Viçosa, MG: Editora UFV, 1999. 443p.

BEWLEY, J. D.; BLACK, M. Seeds: physiology of development and germination. New York: Plenum Press, 1994. 445p.

BORGES, E. E. L.; RENA, A. B. Germinação de sementes. In: AGUIAR, I. B.; PINÃ-

RODRIGUES, F. C. M.; FIGLIOLIA, M. B.

Sementes florestais tropicais. Brasília: ABRATES, 1993. p. 83-135.

BRASIL. Ministério da Agricultura e Reforma Agrária. Regras para análise de sementes. Brasília: SNDA/DNDV/CLAV, 1992. 365p.

R. Árvore, Viçosa-MG, v.30, n.3, p.359-367, 2006
CARRIJO, O. A.; LIZ, R. S.; MAKISHIMA, N. Fibra da casca do coco verde como substrato agrícola. Horticultura Brasileira, v. 20, n. 4, p. 533-535, 2002.

FIGLIOLIA, M. B.; OLIVEIRA, E. C.; PINÃRODRIGUES, F. C. M. Análise de sementes. In: AGUIAR, I. B.; PIN Ã-RODRIGUES, F. C. M.; FIGLIOLIA, M. B. Sementes florestais tropicais. Brasília: ABRATES, 1993. p. 137-174.

IBAMA. Lista oficial das espécies da flora ameaçadas de extinção. Diário Oficial. Portaria 006/92-N de 15 de janeiro de 1992.

LACERDA, M. R. B. et al. Germinação de sementes de sabiá (Mimosa caesalpiniaefolia, Benth) em diferentes substratos em condições de viveiro. In: SIMPÓSIO DE PESQUISA E PÓSGRADUAÇÃO DA UFRPE, 5., 2003, Recife. Resumos expandidos... Recife: Universidade Federal Rural de Pernambuco, 2003. CD - Rom.

LANDGRAF, P. R. C. Germinação de sementes de guarea (Guarea guidonea (L.) Sleumer), maçaranduba (Persea pyrifolia) e peito de pombo (Tapirira guianeensis Aul.). 1994. 91f. Dissertação (Mestrado em Agronomia) - Escola Superior de Agricultura de Lavras, Lavras, 1994.

LORENZI, H. Árvores brasileiras: manual de identificação e cultivo de plantas arbóreas nativas do Brasil. 2.ed. Nova Odessa: Plantarum, 1998. v. 1.352p.

MAGUIRE, J. D. Speed of germination-aid in selection and evaluation for seedlings emergence and vigor. Crop Science, v. 2, n. 1, p. $176-177,1962$.

MATOS, F. J. A. Plantas de medicina popular do Nordeste: propriedades atribuídas e confirmadas. Fortaleza: Edições UFC, 1999. 80p.

NASSIF, S. M. L.; VIEIRA, I. G.; FERNANDES, G. D. Fatores externos (ambientais) que influenciam na germinação de sementes. Disponível em: <http://www.ipef.br/ tecsementes/germinacao.html>. Acesso em: 03 ago. 2004. 
NUNES, Y. R. F. et al. Germinação de sementes das espécies arbóreas mais importantes da Área de Reserva da Barragem do Rio Juramento. Montes Claros: UNIMONTES, 2002. 60p. (Relatório Técnico).

OLIVEIRA, T. V. S.; RANAL, M. A.; SANTANA, D. G. Emergência de plântulas de Matayba guianensis Aubl. (Sapindaceae) ocorrente na região do Triângulo Mineiro. Informativo ABRATES, v. 13, n. 3, p. 337, 2003.

POPINIGIS, F. Fisiologia da semente. Brasília: AGIPLAN, 1985.289p.

PROBERT, R. J. The role of temperature in germination ecophysiology. In: FENNER, M. Seeds: the ecology of regeneration in plant communities. Wallingford: CABI, 1992. p. 285-325.

RODRIGUES, L. V. Análise morfológica e morfométrica da colite induzida por ácido acético, em ratos, e tratada com extratos vegetais (Myracrodruon urundeuva Fr. All.). 1999. 50f. Tese (Doutorado em Técnica Operatória e Cirurgia Experimental) - Universidade Federal de São Paulo, São Paulo, 1999.
SANTOS, S. R. G.; AGUIAR, I. B. Germinação de sementes de branquilho (Sebastiania commersoniana (Baill.) Smith \& Downs) em função do substrato e do regime de temperatura. Revista Brasileira de Sementes, v. 22, n. 1, p. 120-126, 2000.

SILVA, J. B.; NAKAGAWA, J. Estudos de fórmulas para cálculo de velocidade de germinação. Informativo ABRATES, v. 5, n. 1, p. 62-73, 1995.

SILVA, V. P. et al. Influência da temperatura e luz na germinação de sementes de cambará (Vochysia haenkiana Mart.). Revista Agricultura Tropical, v. 4, n. 1, p. 99-108, 2000.

SILVA, L. M. M.; RODRIGUES, T. J. D.;

AGUIAR, I. B. Efeito da luz e da temperatura na germinação de sementes de aroeira (Myracrodruon urundeuva Allemão). Revista Árvore, v. 26, n. 6, p. 691-697, 2002.

SILVEIRA, E. B. et al. Pó de coco como substrato para produção de mudas de tomateiro. Horticultura Brasileira, v. 20, n. 2, p. 211-216, 2002.

VAVRINA, C. S. et al. Coconut coir as na alternative to pear meaia for vegetable transplant production. Station Rpt.-Veg, v. 4, p. 1-8, 1996. 